\title{
Operational Considerations for Oxygen Flammability Risks; Concentrated Oxygen Diffusion and Permeation Behaviors
}

\author{
Susana Harper, ${ }^{1}$ Sarah Smith ${ }^{2}$, Alfredo Juarez ${ }^{3}$, David Hirsch, ${ }^{4}$ \\ NASA White Sands Test Facility, Las Cruces, NM, 88004
}

\begin{abstract}
Increased human spaceflight operations utilize oxygen concentrations that are frequently varied with use of concentrations up to 100 percent oxygen. Even after exiting a higher percentage oxygen environment, high oxygen concentrations can still be maintained due to material saturation and oxygen entrapment between barrier materials. This paper examines the material flammability concerns that arise from changing oxygen environments during spaceflight operations. We examine the time required for common spacecraft and spacesuit materials exposed to oxygen to return to reduced ignitability and flammability once removed from the increased concentration. Various common spacecraft materials were considered: spacecraft cabin environment foams, Extra Vehicular Mobility Unit materials and foams, Advanced Crew Escape Suit materials, and other materials of interest such as Cotton, Nomex ${ }^{\circledR}$ HT90-40, and Tiburon Surgical Drape. This paper presents calculated diffusion coefficients derived from experimentally obtained oxygen transmission rates for the tested materials and the analytically derived times necessary for reduced flammability to be achieved based on NASA flammability criteria. Oxygen material saturation and entrapment scenarios are examined. Experimental verification data on oxygen diffusion in saturation scenarios are also presented and discussed. We examine how to use obtained data to address flammability concerns during operational planning to reduce the likelihood of fires while improving efficiency for procedures.
\end{abstract}

Keywords

Flammability, Nonmetals, Permeation, Diffusion, Maximum Oxygen Concentration (MOC), Gaseous Oxygen Enrichment, Textiles, Extravehicular Mobility Unit, Crew Escape Suit, Clothing, Saturation

${ }^{1}$ Standard Testing and Flammability Engineer and Manager, NASA Johnson Space Center White Sands Test Facility, P.O. Box 20, Las Cruces, NM, 88004.

2 Oxygen Systems Engineer, NASA Johnson Space Center White Sands Test Facility, P.O. Box 20, Las Cruces, NM, 88004.

${ }^{3}$ Flammability System Engineer, Jacobs Technology, Inc., NASA Johnson Space Center White Sands Test Facility, P.O. Box 20, Las Cruces, NM, 88004.

${ }^{4}$ Standard Test and Flammability Engineer and Supervisor, Jacobs Technology, Inc., NASA Johnson Space Center White Sands Test Facility, P.O. Box 20, Las Cruces, NM, 88004. 


\section{Introduction}

NCREASED human spaceflight operations utilize oxygen concentrations that are frequently varied with use of concentrations up to 100 percent oxygen. Even after exiting a higher percentage oxygen environment, high oxygen concentrations can still be maintained due to material saturation and oxygen entrapment between barrier materials. Catastrophic fires have occurred as a result of gaseous oxygen enrichment, even in low pressure environments. One contributing factor is that textile materials become more flammable and easier to ignite after exposure to gaseous oxygen enrichment or saturation. In addition, these materials can serve as barriers by trapping localized oxygen-enriched environments.

When materials are moved from a higher oxygen concentration environment to an environment with lower oxygen concentration, the corresponding flammability and ignitability risks are difficult to characterize. An aerospace example of such a scenario would occur when an astronaut completes an extravehicular activity (EVA) performed in 100 percent oxygen, and then moves into a spacecraft with a lower oxygen concentration (such as 34 percent oxygen). A ground support example of such a scenario would occur when a person performs liquid oxygen-filling operations and is exposed to a high amount of oxygen vapor. In each of these scenarios, the duration of time for the person's garments to return to the flammability and ignitability expected in the lower oxygen concentration is uncertain. The generally accepted rule of thumb has been to allow $30 \mathrm{~min}$ for materials to return to their expected flammability and ignitability state in the lower oxygen concentration (and avoid any potential ignition sources during that 30 -min time frame). ${ }^{1}$ However, this was not based on data and was established as a presumably conservative estimate. This paper examines calculations and experimental data to understand how well this rule of thumb lines up with reality. Understanding the true times needed for appropriate diffusion will help guide how operations can be conducted to minimize oxygen enrichment flammability concerns and time lost. This is of particular concern in the case of an astronaut moving back and forth between different environments where there is the need to be as efficient as possible. Understanding these issues will be of particular importance for our operations as we move to vehicles and planetary bases where quick transition between oxygen environments will become necessary and routine.

NASA Johnson Space Center (JSC) White Sands Test Facility (WSTF) developed a test and analysis approach to relate oxygen diffusion rates with flammability of materials that have been exposed to oxygen-enriched environments. This report examines two oxygen enrichment scenarios, the scenario of saturation of materials exposure to oxygenenriched environments, and the scenario of entrapment when materials function as a potential barrier to create localized high oxygen concentrations. The entrapment scenario is particularly focused on simulating oxygen trapped between a material and a person's body. These two scenarios are depicted in Figure 1.

\section{Oxygen Saturation Scenarlo Oxygen Entrapment Scenario}
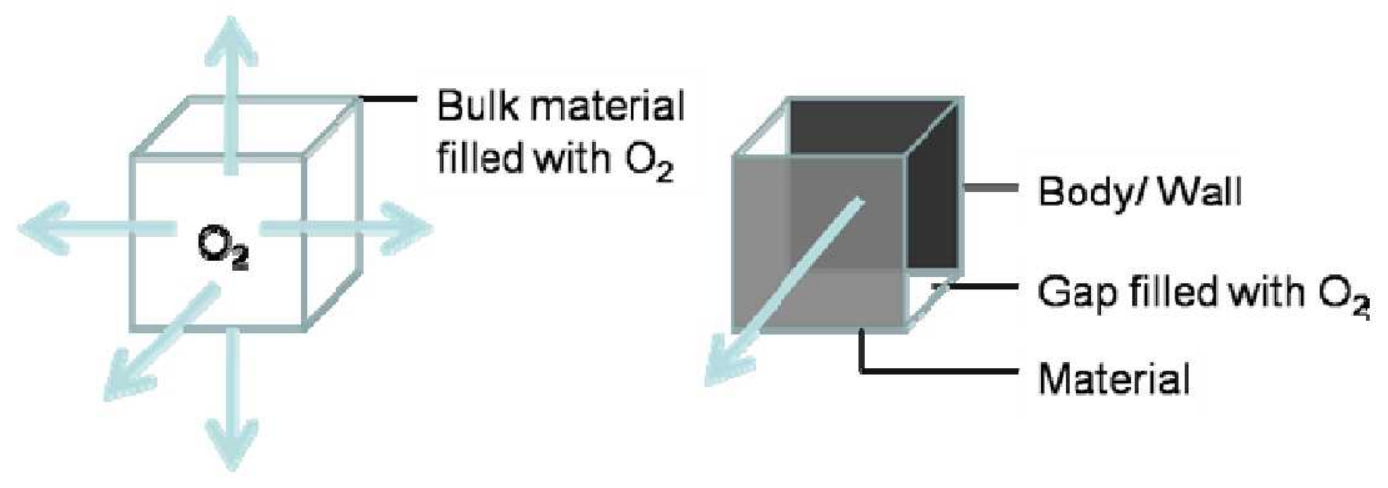

Figure 1. Oxygen Saturation and Entrapment Scenarios for Oxygen Concentration Decay Diffusion Analysis 


\section{Test Methodology}

The goal in developing the test methodology was to characterize flammability as a function of time, thereby relating the flammability to the diffusion of oxygen out of concentrated areas and materials in entrapment and saturation scenarios. It was determined that a two-phase approach could be used and data correlated. The two phases of the methodology were diffusion calculations and testing and flammability testing. In the diffusion phase, mass transport calculations were performed to theoretically correlate how the concentration of oxygen would vary with time for a specified configuration. Material diffusion testing was performed in this phase to obtain critical diffusion values required for mass transport calculations. In the flammability phase, material flammability testing was performed to determine what concentration would be considered a reduced flammability environment for each material. The approximate time for a material exposed to 100 percent oxygen to reach this reduced flammability concentration is then the recommended diffusion time for personnel or materials to wait before resuming normal operations. A flow chart of methodology is given in Figure 2.

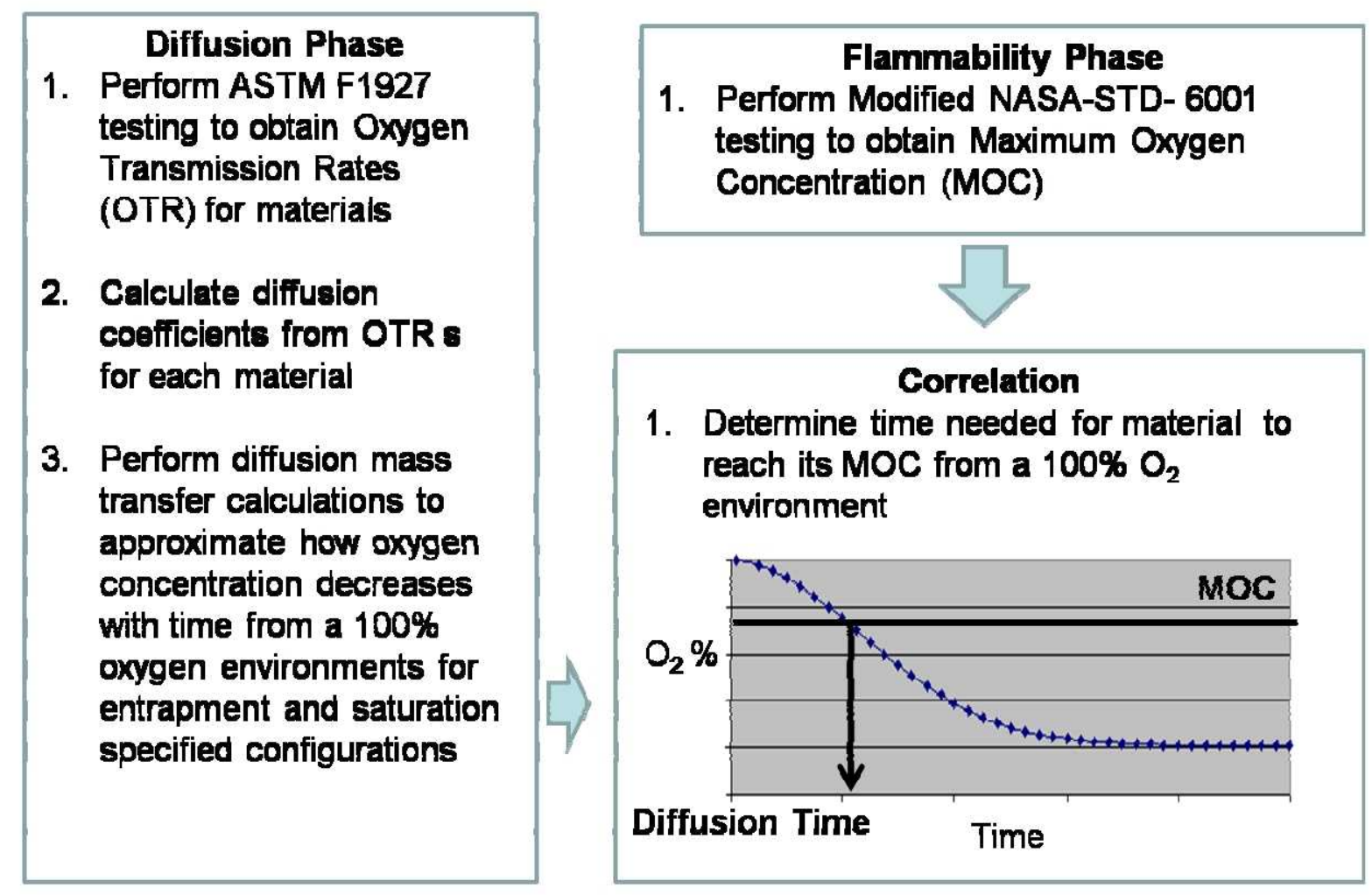

Figure 2. Approximation of Time Required for Materials Exposed to Oxygen to Return to Reduced Flammability Methodology

To obtain diffusion coefficients, testing was performed. Testing generated oxygen-transmission rate data (absolute flux). Rearrangement of Fick's First law of Diffusion for a steady-state stationary medium, with known concentrations and material thicknesses, allowed the derivation of material and gas specific diffusion coefficients. Testing was performed in accordance with ASTM-F1927. ${ }^{2}$ This test method determines the rate of transmission of oxygen gas at steady-state conditions at a given temperature and percent relative humidity (\% $\mathrm{RH})$ through films, sheeting, laminates, co-extrusions, or plastic coated papers and fabrics.

For entrapment and porous saturation scenarios it was assumed that the full volume of the defined space was filled with 100 percent oxygen. In the entrapment scenario, the model simulates oxygen trapped between an impermeable surface (human body) and that of a barrier material. The gap between these two is $1 \mathrm{~cm}$ deep and filled with oxygen. Diffusion was assumed to take place only through the main face area and not through the sides. For saturation scenarios, bulk materials were modeled as a cube with a side length of $0.5 \mathrm{~m}$. Diffusion was assumed to take place through all six faces of the cube. For porous materials, it was assumed that the full volume of the modeled cube was filled with 100 percent oxygen. 
For saturation of non-porous materials, the amount of oxygen that is actually in the cube volume is limited by the extent to which a material can absorb a gas. If treated as a uniform substance, the concentration of the gas in the solid may be obtained through the use of a property known as the solubility. Due to limited solubility information, materials were assumed to have equal solubility to that of the published solubility of oxygen in rubber at $298 \mathrm{~K}{ }^{3}$ Volumes and solubility relationships were used to define initial concentration and mole quantities for diffusion calculations. All approximations were made assuming a well-mixed external atmospheric environment of 20.9 percent.

Flammability testing was conducted to determine the maximum oxygen concentration (MOC) at which a material will be acceptable for use without restrictions per NASA-STD-6001 requirements for NASA vehicles. NASA requires that all non-metallic materials pass NASA-STD-6001A, Test 1 flammability testing. Materials are required to self extinguish before a burn length of 6 inches is reached with no dripped, burning material that propagates fire to a $\mathrm{K}-10$ paper set below the sample in a static environment. ${ }^{5}$ The test setup was a modified NASA-STD-6001A, Test 1 configuration non-edge ignition was performed to better simulate a realistic ignition scenario.

To determine the MOC threshold, the NASA-STD-6001, Test 1 flammability test is performed at incrementally higher concentrations until a threshold is established between a concentration in which the material will fail, burning longer than 6 inches, and one in which five samples will pass, self-extinguishing prior to burning 6 inches. ${ }^{5}$ The MOC threshold established for each material can be considered an upper boundary below which materials exhibit reduced flammability with self-extinguishment characteristics. In this paper and for NASA programs, the MOC threshold will be the concentration at which we consider the material to have established reduced flammability and standard operations may proceed.

Experimental validation testing was also performed on a limited quantity of materials and configurations. This was done to examine validity of assumptions in modeling and to generate a better understanding of oxygen diffusion transport.

\section{Test Materials}

NASA groups that encounter operational challenges with varying oxygen concentrations assisted in developing a list of in-use, at-risk materials for testing. Groups involved in material selection were: the JSC Material and Processes Branch, the Extravehicular Activity Office, and the Crew Escape Suit and Systems Group. Some materials not used in NASA scenarios were chosen for their comparison with past data. ${ }^{2}$ Materials chosen were grouped into separate categories by function and tested in their in-use thickness. Table 1 describes the thirteen materials and layups tested. 
Table 1. Test Materials

\begin{tabular}{|c|c|}
\hline Material & Description \\
\hline \multicolumn{2}{|c|}{ Common/Comparison Fabrics } \\
\hline Nomex ${ }^{\circledR a}$ HT90-40 & $\begin{array}{l}\text { Aramid fabric with high-performance heat- and flame-resistant } \\
\text { properties. L/N } 7254\end{array}$ \\
\hline Tiburon surgical drape & $\begin{array}{l}\text { Microfiber composite consisting of three layers: an absorbent fluid- } \\
\text { control layer made of microfiber fabric, an impermeable cast- } \\
\text { extruded polyethylene membrane laminated to the non-woven } \\
\text { components, and a patient comfort layer }\end{array}$ \\
\hline Cotton Fabric & Cellulose fabric in $100 \%$ cotton Hanes Beefy T-shirt \\
\hline
\end{tabular}

EMU Liquid-Cooled

Ventilation Garment

(LCVG)

Thermal Comfort

Undergarment (TCU)

Spandex-Covered Viton

(Mosite) Foam
Polyamide Material Nylon Tricot ST11N791-01

Polyester-based Material TCU Bottom, P/N SKD38114488-01. $100 \%$ Polyester

Polyurethane/Polyethylene Glycol Elastomeric Spandex

ST11N117-07 Covered Viton (Mosite) Fluoroelastomer Closedcell Foam ST66V2590-01 is used in a variety of pads available for use in the EMU. These pads were designed to reduce hot-spots created by suit contact with the shoulders, elbows, ribs, or knees. The pads are inserted into spandex pockets that are form-fitted to each pad, and these are whip-stitched to the LCVG. ${ }^{6}$

\begin{tabular}{|c|c|}
\hline \multicolumn{2}{|c|}{ Advanced Crew Escape Suit(ACES)/Equipment } \\
\hline ACES Suit Layup & $\begin{array}{l}\text { Layup consisting of two outer layers of ACES, the outer material } \\
\text { composed of the Aramid fiber-based Nomex and the inner material } \\
\text { composed of a Polytetrafluoroethylene (PTFE) based Gore-Tex }{ }^{\circledR b} \\
\text { for use as a bladder. }\end{array}$ \\
\hline $\begin{array}{l}\text { ACES Liquid-Cooled } \\
\text { Garment (LCG) }\end{array}$ & $\begin{array}{l}\text { An assembly composed of thick, polypropylene-based } \\
\text { undergarment with plastic tubing stitched in. This garment is worn } \\
\text { under the outer ACES garment for temperature control. }{ }^{7}\end{array}$ \\
\hline \multicolumn{2}{|c|}{ Cabin Environment Materials } \\
\hline $\begin{array}{l}\text { Minicel }{ }^{\circledR c} \text { Polyethylene } \\
\text { Foam }\end{array}$ & $\begin{array}{l}\text { L-200 Minicel Polyethylene Foam. This foam is extremely fine- } \\
\text { celled, chemically cross-linked closed-cell foam, commonly used } \\
\text { in the various space vehicles. To mitigate fire risks on orbit, this } \\
\text { foam is commonly wrapped in the flame-resistant material Nomex. }\end{array}$ \\
\hline Minicel Polyethylene & HT90-40 Nomex Covered L-200 Minicel Polyethylene Foam. This \\
\hline Foam with Nomex & foam is closed-cell foam, commonly used in the various space \\
\hline Covering & vehicles. \\
\hline Pyrell $^{\circledR \mathrm{d}}$ Polyurethane & Pyrell Polyurethane Foam. This foam is open-celled foam. \\
\hline Foam & \\
\hline Zotek $^{\circledR e}$ F-30 Foam & $\begin{array}{l}\text { Polyvinylidene Flouride (PVDF), and pure thermoplastic } \\
\text { fluoropolymer closed-cell foam; a foam being considered for } \\
\text { extensive use in future NASA vehicles due to its flame resistance. }\end{array}$ \\
\hline \multicolumn{2}{|c|}{ 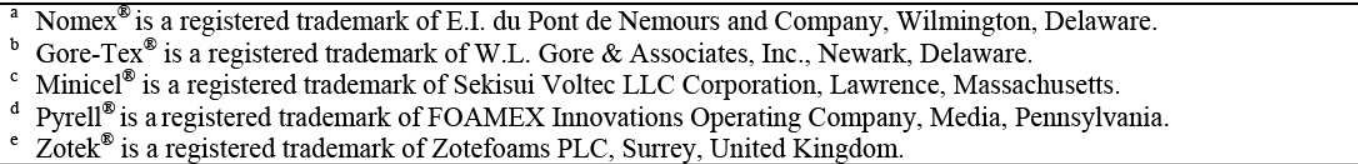 } \\
\hline
\end{tabular}




\section{Oxygen Decay Modeling}

Results from testing necessary for calculations and correlations are presented and discussed below, as well as the results of oxygen decay modeling in entrapment and saturation scenarios.

ASTM-F1927 was conducted at the specified temperature and \% RH expected during material usage to determine absolute flux and diffusion coefficients for non-porous materials. Results of these tests are shown in Table 2 and Figure 3. Materials that cannot contain a gas, such as common clothing materials, are considered porous and exhibit free diffusion. The ACES layup was questionable and was tested using ASTM-F1927. Testing showed that the layup was indeed porous. Materials that were determined to be porous exhibit free diffusion for which a published value for oxygen through air was used. ${ }^{3}$ Porous materials and free diffusion value are presented in Table 3.

\section{Table 2. Non-Porous Materials and Their Calculated Diffusion Coefficients}

\begin{tabular}{|c|c|c|c|c|}
\hline \multirow[b]{2}{*}{ Material } & \multicolumn{3}{|c|}{ Analysis Conditions } & \multirow[b]{2}{*}{$\begin{array}{l}\text { Diffusion Coefficient } \\
\qquad \frac{\mathrm{Mol} \cdot \mathrm{m}}{\mathrm{m}^{2} \cdot \mathrm{S} \cdot \mathrm{Pa}}\end{array}$} \\
\hline & $\underset{\text { (F) }}{\text { Temp }}$ & $\begin{array}{l}\text { Test Gas } \\
\left(\mathrm{O}_{2}\right) \\
\text { Humidity } \\
\text { (RH \%) }\end{array}$ & $\begin{array}{c}\text { Carrier Gas }\left(\mathrm{N}_{2}\right) \\
\text { Humidity } \\
\text { (RH \%) }\end{array}$ & \\
\hline Tiburon Surgical Drape & 75 & $35 \%$ & $35 \%$ & $1.4018 \mathrm{E}-14$ \\
\hline Spandex-Covered Viton (Mosite) Foam & 72 & $47 \%$ & $35 \%$ & $4.1486 \mathrm{E}-15$ \\
\hline Minicel Polyethylene Foam & 75 & $35 \%$ & $35 \%$ & $1.3362 \mathrm{E}-13$ \\
\hline $\begin{array}{l}\text { Minicel Polyethylene Foam with } \\
\text { Nomex Covering }\end{array}$ & 75 & $35 \%$ & $35 \%$ & $1.3543 \mathrm{E}-13$ \\
\hline Zotek F-30 Foam & 75 & $35 \%$ & $35 \%$ & $3.4117 \mathrm{E}-13$ \\
\hline
\end{tabular}

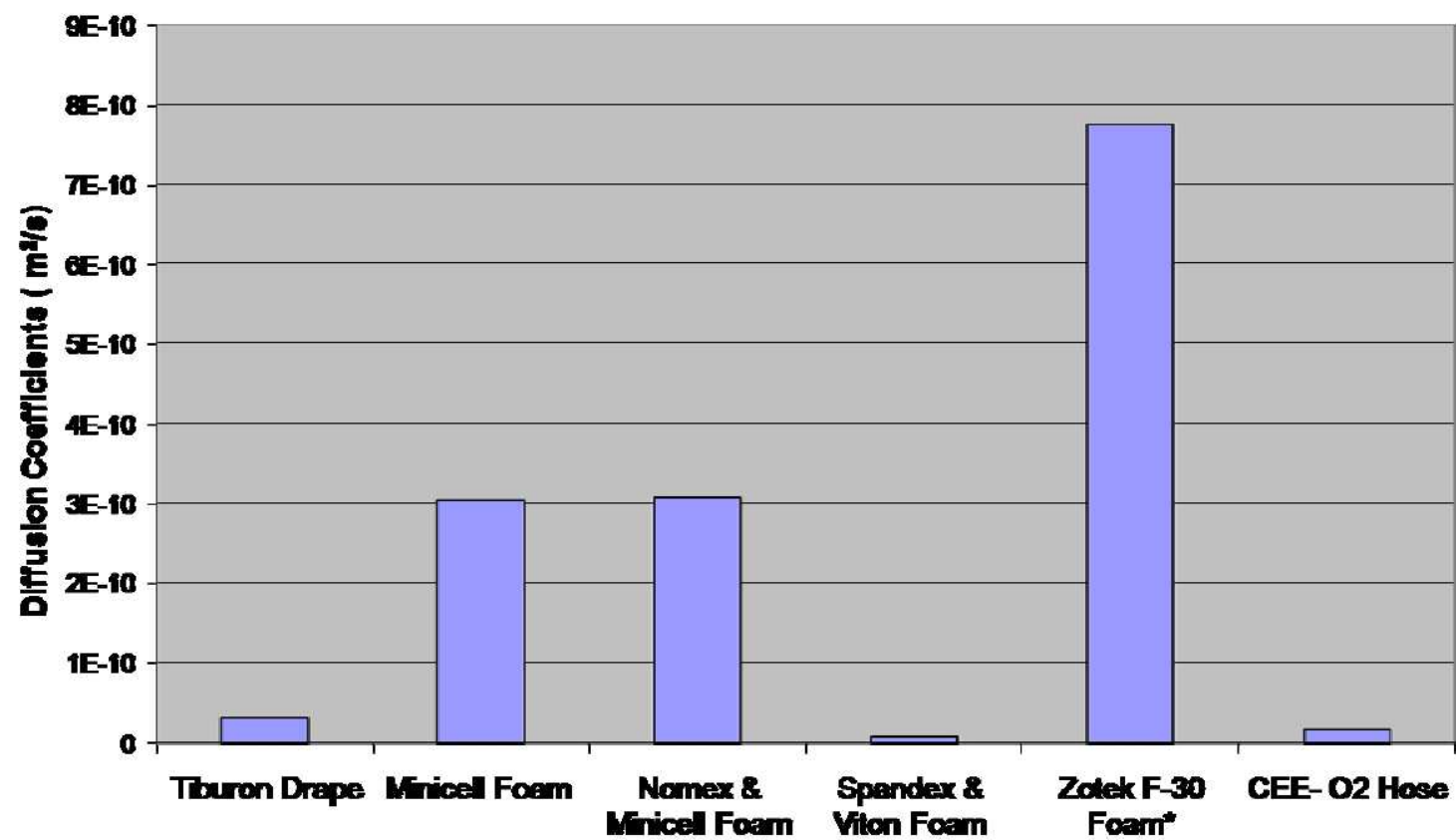

Figure 3. Diffusion Coefficients for Non-Porous Materials 
Table 3. Porous Materials and Their Diffusion Coefficient

\begin{tabular}{lc}
\hline \hline \multicolumn{1}{c}{ Material } & $\begin{array}{c}\text { Natural Oxygen Gas Diffusion Coefficient } \\
\text { air a 278K and 1 atm (m^ } \mathbf{~ 2 / s )}\end{array}$ \\
\hline Nomex HT90-40 & $2.1 \mathrm{E}-05$ \\
Cotton Fabric & $2.1 \mathrm{E}-05$ \\
EMU Liquid-Cooled Ventilation Garment (LCVG) & $2.1 \mathrm{E}-05$ \\
Thermal Comfort Undergarment (TCU) & $2.1 \mathrm{E}-05$ \\
ACES Suit Layup & $2.1 \mathrm{E}-05$ \\
ACES Liquid-Cooled Garment (LCG) & $2.1 \mathrm{E}-05$ \\
Pyrell Polyurethane Foam & $2.1 \mathrm{E}-05$ \\
\hline \hline
\end{tabular}

NASA- STD-6001A Maximum Oxygen Concentration (MOC) flammability testing was conducted at specified environmental pressure while the oxygen concentration was varied to determine the flammability threshold. Though the actual materials are used in a variety of pressure and concentration combinations, a single worst-case pressure of $101 \mathrm{kPa}$ (14.7 psia) was chosen for consistency and ease of data comparison. ${ }^{8} \mathrm{MOC}$ threshold results are shown in Tables 4 and 5 for non-porous and porous materials, respectively.

Diffusion coefficients were used in calculations to determine oxygen concentration dependence with time for each material in its specific configuration for either entrapment or saturation modeling. From these, oxygen decay plots were generated. It should be noted that thicknesses were chosen to represent in-use thicknesses of materials. If material thicknesses were to be varied, this would have an effect on time needed for diffusion to occur.

The point at which oxygen concentration decay intercepts MOC was determined as the point in time when operations can proceed without risk for increased flammability. Below this threshold we can assume decreased flammability and return to normal operations for a given material. This correlation was depicted earlier in this paper and can be found in Figure 2.

\section{Clothing Oxygen Entrapment Decay Time Modeling}

The entrapment scenario represents oxygen found between clothing and a person's body. Tables 4 and 5 show the calculated amount of time needed for the entrapped area to reach the MOC threshold. In cases where the MOC is below ambient oxygen concentrations of 20.9 percent, the time calculated was the time to reach ambient conditions, where the lowest concentrations are commonly encountered.

Table 4. Non-Porous Materials Time for MOC Oxygen Concentration Decay for $1 \mathrm{~cm}$ Gap Entrapment Scenario

\begin{tabular}{l|c|c|c}
\hline \hline \multicolumn{1}{c|}{ Material } & $\begin{array}{c}\text { Thickness } \\
(\mathbf{m})\end{array}$ & $\begin{array}{c}\text { MOC } \\
(\mathbf{\%})\end{array}$ & $\begin{array}{c}\text { Time (t) for MOC } \\
\text { hr:min:sec (O2\%) }\end{array}$ \\
\hline Tiburon surgical drape & 0.00022 & 20 & $05: 10: 01(20.9)$ \\
Spandex-Covered Viton (Mosite) Foam & 0.00794 & 18 & $447: 18: 21(20.9)$ \\
Minicel Polyethylene Foam & 0.05100 & 20 & $36: 55: 01(20.9)$ \\
Minicel Polyethylene Foam with Nomex Covering & 0.05169 & 28 & $13: 34: 59$ \\
Zotek F-30 Foam & 0.0254 & 36 & $04: 49: 59$ \\
\hline \hline
\end{tabular}


Table 5. Porous Materials Time for MOC Oxygen Concentration Decay for $1 \mathrm{~cm}$ Gap Entrapment Scenario

\begin{tabular}{|c|c|c|c|}
\hline Material & $\begin{array}{c}\text { Thickness } \\
(\mathbf{m})\end{array}$ & MOC (\%) & $\begin{array}{l}\text { Time (t) for MOC } \\
\text { hr:min:sec }\left(\mathrm{O}_{2} \%\right)\end{array}$ \\
\hline $\begin{array}{l}\text { EMU Liquid-Cooled Ventilation Garment } \\
\text { (LCVG) } \\
\text { Pyrell Polyurethane Foam }\end{array}$ & $\begin{array}{l}0.00022 \\
0.0508\end{array}$ & $\begin{array}{l}23 \\
19(20.9)\end{array}$ & $\begin{array}{l}00: 00: 026 \\
00: 00: 10\end{array}$ \\
\hline
\end{tabular}

Because free oxygen diffusion takes place through all porous materials, the only variation in diffusion time for these materials is their dependence on thickness. Table 5 presents the thickest and thinnest porous materials tested to give a range of time for decreased flammability.

Non-porous materials perform as excellent barriers for oxygen entrapment. To minimize flammability risks as well as time restrictions these should be given carefully considered in design of systems and suit configurations as well as in operational planning. Design consideration should be given to the choice of materials and their barrier performance qualities as well as to ensuring pockets that can serve as containments for high oxygen concentrations are not created. A closed-cell, foam-lined cabin wall with void space behind it could become such a pocket if small leaks allowed high oxygen concentration to fill the space over an extended period of time, while limiting the ability of the concentrated oxygen to escape. Non-porous materials and their potentially entrapped high oxygen concentrations can also be addressed operationally by defining pocket locations and providing the proper gas exchange past barriers materials to ensure sufficient dilution and diffusion occurs. This is especially clear with Mosite Foam, with a required 447 hours to allow a $1 \mathrm{~cm}$ depth of oxygen behind it to diffuse. Mosite foam is closed-cell foam, in contrast with the tested open-celled polyurethane foam that allows diffusion of entrapped oxygen into the surrounding atmosphere in a matter of seconds. Localized, enriched oxygen concentrations should be considered in operational planning, especially as there is a move toward greater use of closed-cell foams. This is particularly alarming when we consider that Mosite foam is used in the astronaut Liquid-Cooled Ventilation Garment (LCVG) that is worn below the EVA suit and can be worn after a mission is complete and the suit is removed. Here the astronaut would retain enriched-oxygen concentrations, trapped in contact with his body for extended periods of time. For porous materials, the 30-min rule of thumb may be overly conservative.

\section{Material Oxygen Saturation Decay Time Modeling}

The saturation scenario models the case of a bulk material saturated in oxygen. Saturation is a concern for larger, bulkier materials as they can hold the largest quantity of oxygen when saturated. Tables 6 and 7 below gives the approximate time for a saturated material to permeate out enriched oxygen and equilibrate to reach the MOC threshold, or 20.9 percent oxygen if the MOC was determined to be below 20.9 percent oxygen. The data presented here is for the time to reach the corresponding environmental concentration derived from the partial pressure, pertaining to the internal oxygen concentration absorbed within the material. The concentration that is found within the material is also listed.

Table 6. Non-porous Materials Time for MOC Oxygen Concentration Decay for $0.5 \mathrm{~m}$ Length Cube Saturation Scenario and $\mathrm{O}_{2}$ in Solid Rubber Solubility

\begin{tabular}{lcccc}
\hline \hline \multicolumn{1}{c}{ Material } & $\begin{array}{c}\text { Thickness } \\
(\mathrm{m})\end{array}$ & $\begin{array}{c}\text { MOC } \\
(\%)\end{array}$ & $\begin{array}{c}\text { Time (t) for Corresponding } \\
\text { MOC hr:min:sec }\left(\mathrm{O}_{2} \%\right)\end{array}$ & $\begin{array}{c}\text { Internal Material } \\
\mathrm{O}_{2} \%\end{array}$ \\
\hline Spandex-Covered Viton (Mosite) Foam & 0.50 & 18 & $10,000: 00: 00(20.9)$ & 2.47 \\
Minicel Polyethylene Foam & 0.50 & 20 & $3050: 00: 00(20.9)$ & 1.48 \\
Minicel Polyethylene Foam with Nomex & 0.50 & 28 & $350: 00: 00$ & 1.98 \\
Covering & 0.50 & 36 & $121: 00: 00$ & 2.54 \\
Zotek F-30 Foam &
\end{tabular}


Table 7. Porous Materials Time for MOC Oxygen Concentration Decay for $0.5 \mathrm{~m}$ Length Cube Saturation Scenario

\begin{tabular}{lccc}
\hline \hline Material & $\begin{array}{c}\text { Thickness } \\
(\mathbf{m})\end{array}$ & MOC (\%) & $\begin{array}{c}\text { Time (t) for MOC } \\
\text { hr:min:sec (O) }\end{array}$ \\
\hline Pyrell Polyurethane Foam & 0.50 & 19 & $00: 02: 10(20.9)$ \\
\hline \hline
\end{tabular}

Based on assumptions in the saturation scenario, non-porous materials also can exhibit the highest level of oxygen containment and risk with extreme potential times for oxygen saturation to be fully diffused from the interior of a material. There is little understanding as to how absorbed oxygen contributes to the increased flammability of the material. There is a possibility that this internal concentration greatly contributes to the speed of combustion, or it is possible that this quantity is too small compared to the quantity of the solid material to support combustion. This is studied more extensively during the experimental examination. For porous materials, the 30 -min rule of thumb may be overly conservative.

\section{Oxygen Decay Experimental Examination}

Modeling of oxygen saturation in materials is challenging due to the limited understanding as to the solubility of oxygen in and out of a material and furthermore, how absorbed oxygen contributes to the increased flammability of the material. Once absorbed, internal oxygen may contribute to the speed of combustion, or it is possible that though absorbed concentration may be high that this quantity is too small compared to the quantity of the solid material to enhance combustion. An experimental examination was performed to define how well modeled scenarios agree with real life phenomenon.

Experimental testing consisted of burning materials at time intervals after being removed from 100 percent oxygen environments. The intent of the study was to obtain burn lengths and burn rates at time intervals and compare these values to those of material flammability tests conducted at specified concentrations. A small subset of materials was tested. Materials were chosen due to interest, replication of modeled configurations, and availability. Unfortunately, due to limited quantity of materials available, experimental configurations could not always replicate modeled materials and layups. Nonetheless, they give valuable information on modeling correlations to physical combustion phenomenon. Testing was focused on a variety of foams, material layups, and a combination of these.

To first examine the question of oxygen solubility and oxygen saturation times, and effect on flammability, a small study was conducted. This allowed a greater understanding of oxygen saturation of foams, assisting in the definition of test parameters for experimental testing. Mosite Viton Closed-Cell foam was conditioned in 100 percent oxygen overnight, and also for $15 \mathrm{~min}$ before test. After the conditioning period was completed, both materials were exposed to reduced oxygen concentration environments for equal amounts of time and tested for flammability. No discernable difference was noted in burn length and burn rate data. It can be assumed the sample that was soaked overnight had absorbed a higher concentration of oxygen due to solubility. The fact that no discernable difference was noted in flammability parameters indicates that while absorbed concentration may be high, this quantity may be too small compared to the quantity of the solid material to enhance combustion. Additional checks were also performed on L-200 Minicel Polyethylene foam at $15 \mathrm{~min}, 30 \mathrm{~min}$, and $45 \mathrm{~min} 100$ percent oxygen soak time. Flammability testing was again conducted at equal times post exposure to reduced oxygen environment without any observable differences in flammability parameters. As a result, $20 \mathrm{~min}$ was used as a presoak material time for experimental testing.

ACES layups were also tested for presoak time sensitivity. The layup was tested with a $15 \mathrm{~min}$ and a $30 \mathrm{~min}$ soak. In this case, there was an observable difference between the burn lengths of the layups. It appears sufficient time was needed to entrap oxygen between material layers to influence the flammability characteristics of the materials. Results of experimental testing are depicted in Figures 4 through 8. 


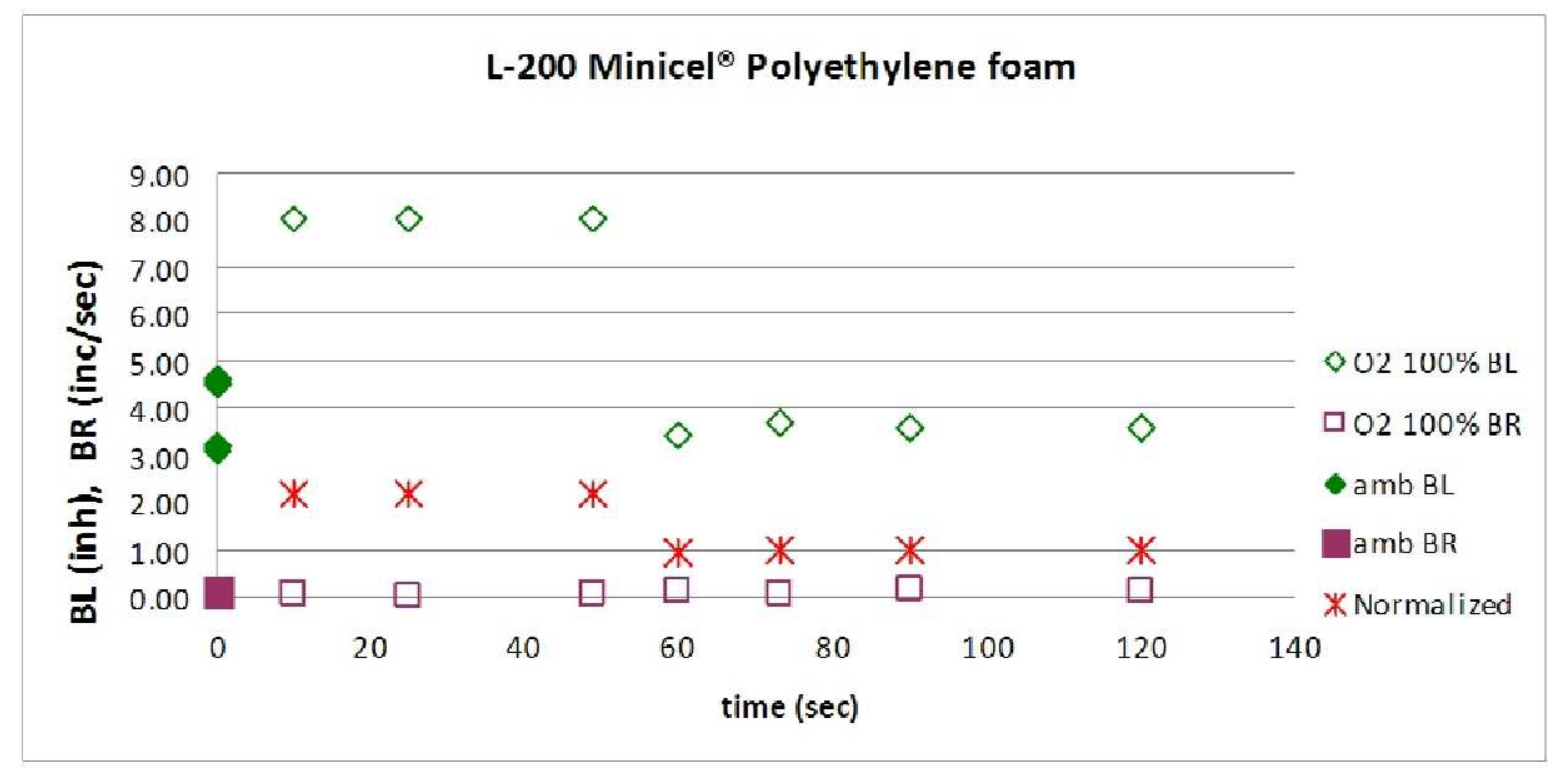

Figure 4. Polyethylene Foam Saturated in 100 Percent Oxygen, Burn Length (BL) and Burn Rate (BR) Effect with Respect to Time After Being Exposed to 20.9 Percent Oxygen Environment

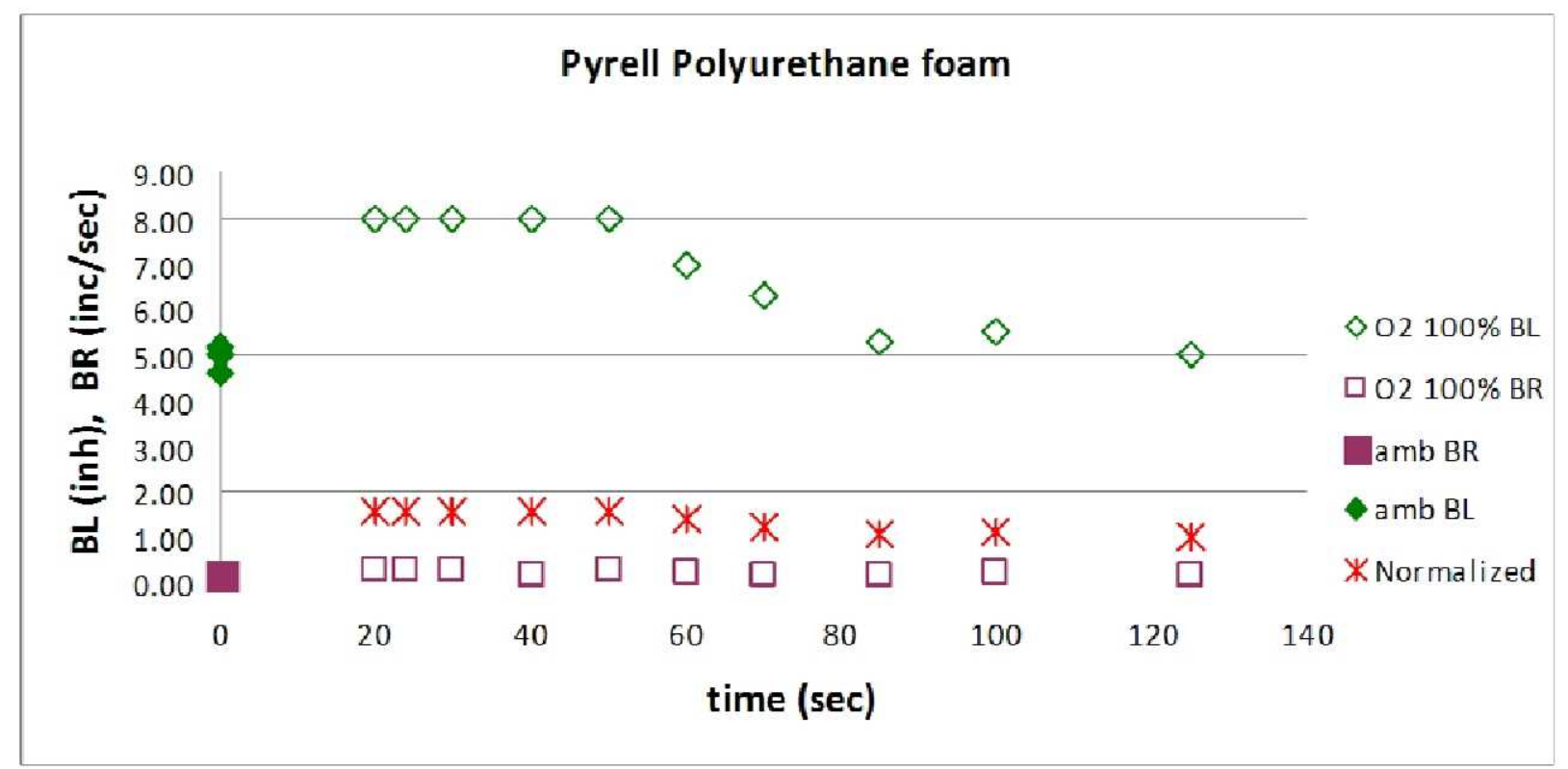

Figure 5. Polyurethane Foam Saturated in 100 Percent Oxygen, Burn Length (BL) and Burn Rate (BR) Effect with Respect to Time After Being Exposed to 20.9 Percent Oxygen Environment 


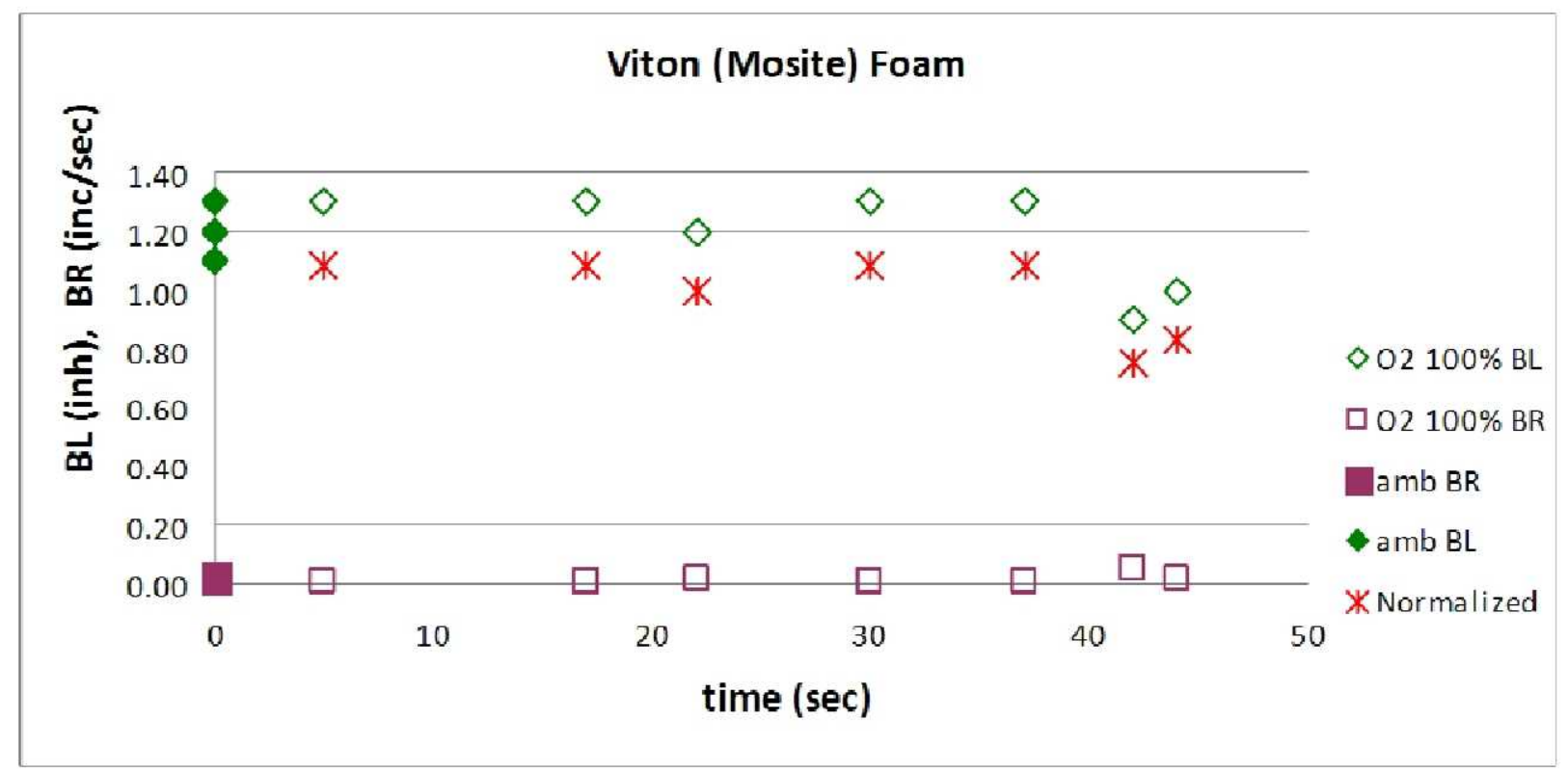

Figure 6. Viton Foam Saturated in 100 Percent Oxygen, Burn Length (BL) and Burn Rate (BR) Effect with Respect to Time After Being Exposed to 20.9 Percent Oxygen Environment

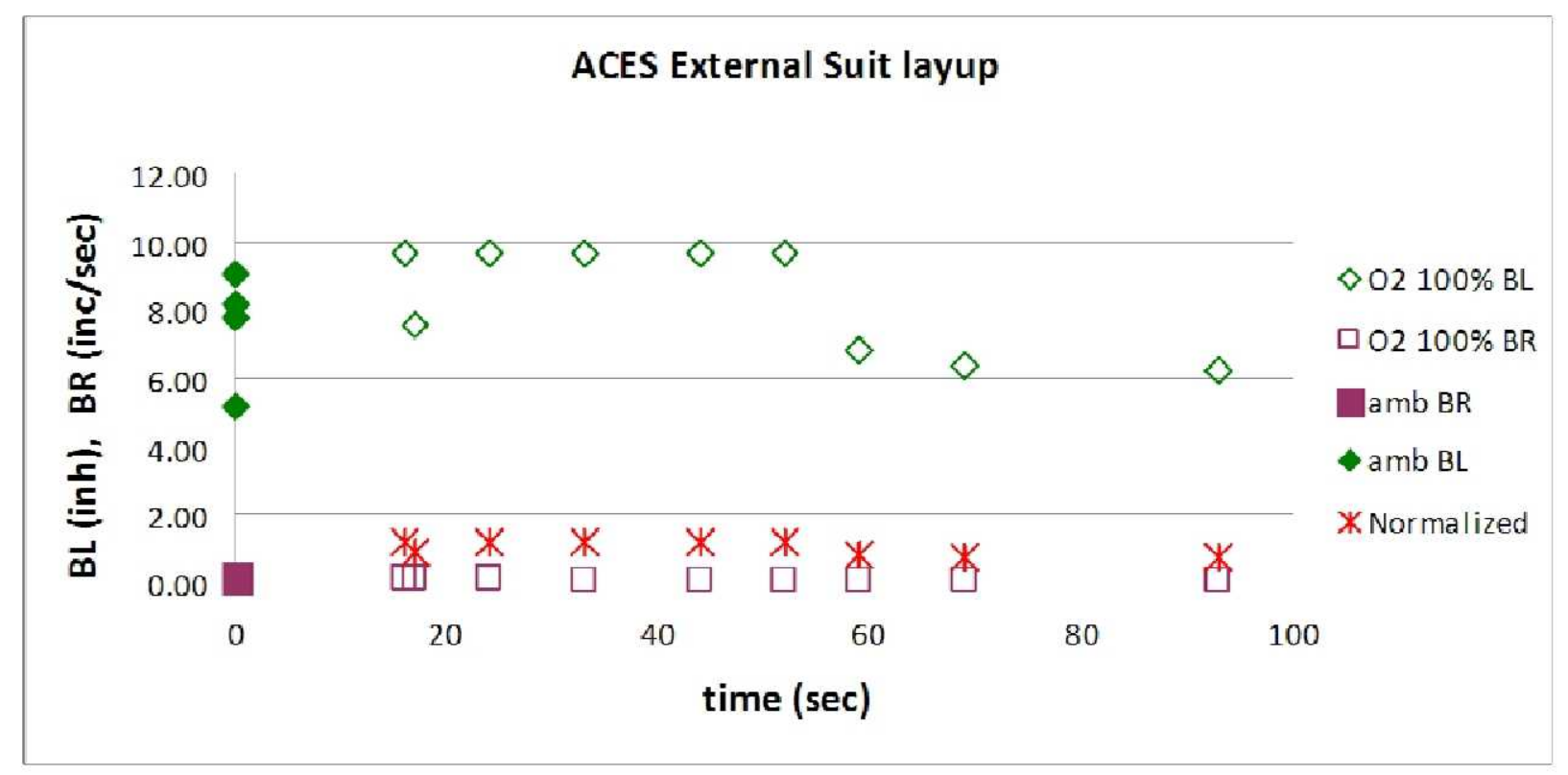

Figure 7. ACES Suit Layup Saturated in 100 Percent Oxygen, Burn Length (BL) and Burn Rate (BR) Effect with Respect to Time After Being Exposed to 20.9 Percent Oxygen Environment 


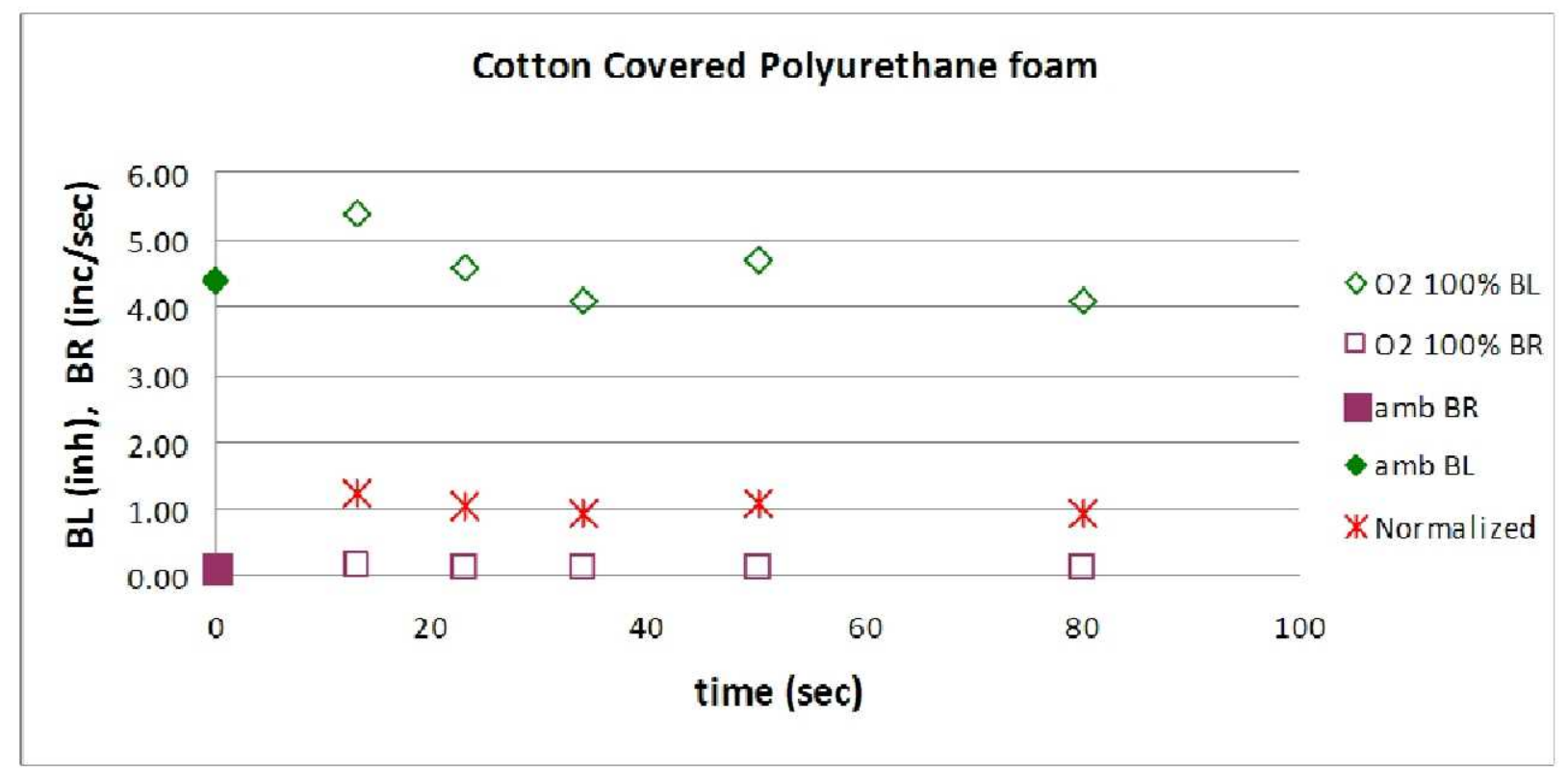

Figure 8. Cotton and Polyurethane Layup Saturated in 100 Percent Oxygen, Burn Length (BL) and Burn Rate (BR) Effect with Respect to Time After Being Exposed to 20.9 Percent Oxygen Environment

From the data generated, we observed that burn rate data in this test configuration was equal at all times, signifying that burn rate is not a good indicator for reduced or increased flammability. Entrapped oxygen concentration in layup configurations appears to have a strong enough influence to affect the flammability characteristics of a material. For bulk materials, soluble oxygen quantity may be too small compared to the quantity of the solid material to enhance combustion.

In general, at $\sim 45-50$ seconds all materials exhibited reduced flammability equal to ambient conditions when looking at burn length. Materials exhibited flammability of their surrounding oxygen environment. With at least small volumes of entrapped oxygen, even layups were minimally affected by small oxygen concentrations that may be retained inside materials, or layers of materials, and reduced in flammability once that oxygen was released through burnt material layup holes. This observed release of entrapped oxygen may occur on a larger scale, but time necessary for diffusion would vary based on the volume of entrapped oxygen. Smoke fog diffusion and flow imaging was performed to examine time for complete dissipation. Flow imaging testing showed that $45-50$ seconds was the time required for fog to fully dissipate from the confined test configuration area.

\section{Conclusion}

From these theoretical approximations, it is clear that oxygen entrapment and saturation can be a real concern and needs to be further investigated, especially when dealing with non-porous materials.

For porous materials, the 30 -min rule of thumb may be overly conservative. From approximations, it can be expected that oxygen concentration will reach reduced flammability conditions in a maximum of $2 \mathrm{~min}$ for a $0.5 \mathrm{~m}$ length bulk material. In the case of clothing, even when entrapment of enriched oxygen occurs, diffusion to reduced flammability conditions should occur in less than a second. Though it is evident that diffusion is relatively quick out of porous materials, precaution should still be taken as there are other associated risks and configuration concerns to take into consideration. Configurationally, a concern would be the exposure of large porous materials, such as a mattress, that may be exposed to an enriched environment. Here the volume for saturation can be very large, yet surface area for diffusion limited. Approximations in this paper assumed diffusion from all six faces of a cube from a bulk sample. In the case of a mattress, at least one of the large faces for diffusion would likely be blocked and significantly decrease the ability of oxygen to diffuse out of the mattress. This would increase the time for achieving reduced flammability via diffusion. It should be noted there is still a risk of oxygen accumulation due to density that may cause oxygen to act as a mass with minimized faces for free diffusion.

For non-porous materials, theoretical approximations suggest that they are excellent at trapping and retaining oxygen. Entrapment approximations give us some meaningful data. Closed-cell foams excel as superior barriers in 
preventing diffusion. This is especially clear with Mosite foam with a required 447 hours to allow a $1 \mathrm{~cm}$ depth of oxygen behind it to diffuse. Localized, enriched oxygen concentrations should be considered in operational planning, especially as there is a move toward a greater use of closed-cell foams.

This is particularly alarming when we consider that Mosite foam is used in the astronaut Liquid-Cooled Ventilation Garment (LCVG) that is worn below the EVA suit and can be worn after a mission is complete and suit is removed. Here the astronaut would retain enriched-oxygen concentrations, trapped in contact with his body for extended periods of time. Another scenario for entrapment is of a NASA vehicle changing from a more enriched environment to a decreased one, as is the case in the air lock. Non-porous materials in cabin walls or in other uses could trap oxygen behind them and maintain enriched concentrations in those pockets from 5 to 447 hours based on configurations analyzed here. In the case of non-porous material entrapment, the 30-min rule of thumb may not be sufficient.

Experimental flammability burn rate and burn length testing was conducted to examine modeled scenario's agreement with real-life phenomenon. From the data generated, we observed that burn rate data, in this test configuration, was equal at all times signifying that burn rate is not a good indicator for reduced or increased flammability. Entrapped oxygen concentration in layup configurations appears to have a strong enough influence to affect the flammability characteristics of a material. For bulk materials, soluble oxygen quantity may be too small compared to the quantity of the solid material to enhance combustion. In general, at $\sim 45-50$ seconds all materials exhibited reduced flammability equal to ambient conditions. Materials exhibited flammability of their surrounding oxygen environment. With at least small volumes of entrapped oxygen, even layups were minimally affected by small oxygen concentrations that may be retained inside materials, or layers of materials, and reduced in flammability once that oxygen was released through burnt material layup holes. This observed release of entrapped oxygen may occur on a larger scale, but time necessary for diffusion would vary based on volume of entrapped oxygen. Smoke fog diffusion and flow imaging were performed to examine time for complete dissipation. Flow imaging testing showed that $45-50$ seconds was the time required for fog to fully dissipate from the confined test configuration area.

It is recommended that particular attention be given to non-porous materials with respect to oxygen entrapment. With non-porous materials, the risks must be weighed to not overly restrict operations, nor to ignore the risk for entrapment and increased flammability. Material selection, configurational design, and operational processes need to be evaluated to reduce the likelihood for oxygen entrapment situations. Testing and approximations here were done in a quiescent environment as this is the worst case scenario for minimizing diffusion. It is recommended that operational considerations include the introduction of bulk flow into confined areas as it would greatly increase the speed at which diffusion takes place.

\section{References}

${ }^{1}$ Beeson, Harold D., Smith, Sarah R., Stewart, Walter F., Safe Use of Oxygen and Oxygen Systems: Handbook for Design, Operation, and Maintenance, $2^{\text {nd }}$ Edition, American Society for Testing and Materials, West Conshohocken, PA, 2007.

${ }^{2}$ ASTM Standard F1927, Standard Test Method for the Determination of Oxygen Gas Transmission Rate, Diffusion and Permeance at Controlled Relative Humidity through Barrier Materials Using a Coulometric Detector, Annual Book of Standards, ASTM International, West Conshohocken, PA, 1999.

${ }^{3}$ Incropera, F., DeWitt, D. Fundamentals of Heat and Mass Transfer, $4^{\text {th }}$ Edition, John Wiley and Sons, New York, NY, 1996.

NASA. Flammability, Offgassing, and Compatibility Requirements and Test Procedures for Materials in Environments that Support Combustion, Interim NASA Technical Standard NASA-STD-(I)-6001A, Test 1, "Upward Flame Propagation," NASA Headquarters, Washington, DC, April 21, 2008.

${ }^{6}$ Sepulveda, R., and Smith, Sarah. "Flammability of Textiles in Air and in Gaseous Oxygen," Flammability and Sensitivity of Materials in Oxygen-Enriched Atmospheres: Eleventh Volume, ASTM STP 1479, D. B. Hirsch, R. Zawierucha, T. A. Steinberg, and H. Barthelemy, Eds., ASTM International, West Conshohocken, PA, 2006.

${ }^{7}$ Williams, D. R and Johnson B .J., EMU Shoulder Injury Tiger Team Report, NASA/TM-2003-212058, NASA Johnson Space Center Houston, TX, September 2003.

${ }^{8}$ Stuart, M. C. Lee, M. S., McDaniel, A., Jacobs, T., and Schneider, S. M., Performance of the Liquid-Cooling Garment with the Advanced Crew Escape Suit in Elevated Cabin Temperatures. NASA/TP-2004-212074. NASA Johnson Space Center, Houston, TX, July 2004. 